\section{Increasing International Stu- dents' Tuition Fees: The Two Sides of the Coin}

\section{Daniel Sanchez-Serra and Gabriele Marcon I}

Daniel Sanchez-Serra and Gabriele Marconi are analysts at the Directorate for Education and Skills, Organisation for Economic Co-operation and Development (OECD). The opinions expressed and arguments employed in this article are solely those of the authors and do not necessarily reflect the official views of the OECD or its member countries. E-mails: daniel.sanchezserra@oecd.org and gabriele.marconi@oecd.org.

$\mathrm{T}$ he existence and level of tuition fees are among the most hotly debated issues in current higher education policy discussions. At least ten OECD countries have implemented reforms in this area since 20I0. However, striking the right balance is not easy. On the one hand, higher tuition fees contribute to better funded tertiary education systems, especially in times of tight public budgets. On the other hand, higher fees can put a burden on families whose children enroll in tertiary education, especially those with limited financial means.

In many countries, however, international students are regarded as a group for which higher tuition fees are less politically controversial. Indeed, in about half of the OECD countries, public educational institutions charge different tuition fees for national and foreign students enrolled in the same programs. In Australia, Austria, Canada, New Zealand, and the United States, foreign students pay on average twice or more the tuition fees paid by national students, while in Denmark and Sweden, tuition fees are charged exclusively to foreign students who come from outside the European Economic Area (EEA). In absolute levels, the difference in tuition fees between national and foreign students can be very large: in all the aforementioned countries (except Austria), this difference exceeds US $\$ 8,000$ per year.

For some countries, the difference in tuition fees depends on geopolitical factors that do not coincide exactly with the distinction between "national" and "foreign." For example, in the United States, national students usually pay the same tuition fees as foreign students if they study in public universities outside of their state of residence. For private universities, there is typically no difference in tuition rates. Alternately, students from the EEA can study in any other country within this area, paying the same tuition fees as national students.
Recent international experiences in tuition fee reforms can inspire other countries looking for evidence. For example, in the last I5 years, Denmark, New Zealand, Sweden and, very recently, Finland, have introduced or modified substantially the tuition fees charged by public institutions to some of their foreign students. Evidence from these reforms (discussed below) shows that foreign students are less willing to select a host country with high tuition fees. However, a substantial number of foreign students continue to enroll, presumably attracted by the perceived quality of education, labour market prospects, or life circumstances in the host countries. These foreign students, who enroll despite the higher tuition fees, can bring substantial economic gains to the host higher education systems.

\section{In many countries, however, interna- tional students are regarded as a group for which higher tuition fees are less po- litically controversial.}

\section{The Financial Contribution of Foreign Students}

The main considerations behind reforms in foreign students' tuition fees are financial. The contribution that foreign students make to the funding of national education systems can be approximated by multiplying their numbers at the bachelor's and master's (or equivalent) levels by the average tuition fees they pay. This figure is then divided by the total expenditure on public and private institutions at the bachelor's, master's, and doctoral (or equivalent) levels, excluding research and development. In 20I3, this ratio, which gives an idea of foreign students' role in funding a higher education system, ranged from more than 25 percent in Australia and New Zealand to I percent in Austria and Sweden.

The large streams of revenue from foreign students' fees that are observed in Australia and New Zealand are due both to the high numbers of fee-paying foreign students and to the comparatively high tuition fees they pay (which exceed US\$I4,000 in both countries). In contrast, the tuition fees paid by foreign students in Austria are relatively low (about US\$II,700 per student per year, on average); in Sweden, the share of foreign students paying higher fees in 2013 was still relatively low (students enrolled before the reform of 2OII-20I2 do not pay tuition fees).

How Do Foreign Students Respond?

In the period from 2004 to 2014 , three OECD countries 
have implemented reforms aimed at changing tuition fees for international students. Evidence from national reforms implemented in Denmark, New Zealand, and Sweden shows that tuition fees and the number of new international entrants are strongly related.

In 2006 , New Zealand introduced a policy that aimed to attract international students to join PhD programs by subsidizing their tuition fees, similarly to national students. Attraction and retention of international students were also promoted by granting them and their partners some rights to work in the country. This policy proved effective the same year of its implementation, as the number of new international entrants to $\mathrm{PhD}$ programs more than doubled in 2006 and continued growing steadily from 2007 onward.

On the other hand, Denmark (in 2006) and Sweden (in 20II) introduced tuition fees for foreign students in shortcycle tertiary programs (bachelor's, master's, or equivalent degree programs). While national students and students from the EEA did not have to pay tuition fees, new entrants from outside the EEA had to pay over US\$II, O०o in Denmark and over US\$13,000 in Sweden. The year in which the reform became effective saw the number of national and EEA students increase in both countries, while the number of international students fell by 20 percent in Denmark and, even more dramatically, by 80 percent in Sweden.

Higher Tuition Fees for Foreign Students: All Good? Available data shows that foreign students can be made to fund a substantial amount of a tertiary education system's expenditure. They have been called the "cash cows" of tertiary education, in this publication and in other authoritative sources. This has motivated many governments to charge foreign students higher fees than national students.

However, international students can afford to be selective: they are willing to move and have many options. Available evidence shows that the number of international students coming to a country can decline dramatically following an increase in tuition fees.

A reduction in the number of international students can potentially harm a tertiary education system, as international students do not only bring their financial contribution, but also a diversity of perspectives and cultures that improves the educational experience of all students. Discrimination by nationality can also harm the student experience by creating divides between students.

Perhaps because of these reasons, a few months ago, both national and international students in Belgium enrolled at the Free University of Brussels and the Catholic University of Leuven protested strongly to oppose plans to increase tuition fees for international students-and these protests were successful. Charging tuition fees to foreign students can be a tool to boost the funding of tertiary educa- tion, but governments must keep in mind that this tool is, essentially, a double-edged sword.

DOI: http://dx.doi.org/ıo.6oI7/ihe.20I8.92.I02I5

\section{"One Belt One Road" and Central Asia: A New Trend in Internationalization of High- er Education?}

\section{Aısı Lı}

Aisi Li is assistant professor at the Graduate School of Education, Nazarbayev University, Astana, Kazakhstan.E-mail: li.aisi@nu.edu.kz.

Tn his speech at Nazarbayev University, Astana, in 20I3, 1 the Chinese president Xi Jinping proposed the "Silk Road Economic Belt." The proposal, together with the "Maritime Silk Road" venture, has evolved to become the "One Belt One Road" (OBOR) strategy. The Belt covers a vast area along the ancient Silk Road, stretching from China to Europe through Central Asia. Critics see this strategy as the latest projection of China's economic ambitions in the world and another form of its soft power policy. The five Central Asian Republics, Kazakhstan, Kyrgyzstan, Tajikistan, Turkmenistan, and Uzbekistan, responded to OBOR differently. Kazakhstan's Nurly Zhol (Lighted Path) initiative directly tied into OBOR, reflecting the country's ambition to be more than a transit zone between China and Europe. Turkmenistan and Uzbekistan are cautious about Chinese labor force expansion, and have therefore restricted the number of Chinese employees that can be hired for projects in their countries. In higher education, OBOR has made a real impact on Central Asia. Four years on, several questions have arisen regarding the strategy's implications for higher education in China and Central Asia.

\section{China's InVestment in Scholarships}

OBOR's emphasis on fostering relations has inevitably led to connecting the region through education. In his speech, $\mathrm{Xi}$ announced a Io-year plan to provide 30,000 scholarships to students from the member countries of the Shanghai Cooperation Organization (SCO) to study at Chinese universities, and to invite I०,००० teachers and students from the region's Confucius Institutes to participate in training programs in China. Since four out of eight SCO members are Central Asian Republics, such a generous proposal has 